\title{
Revisão: Proteínas anticongelantes - uma tecnologia emergente para o congelamento de alimentos
}

\author{
Review: Antifreeze proteins - an emerging technology for freezing foods
}

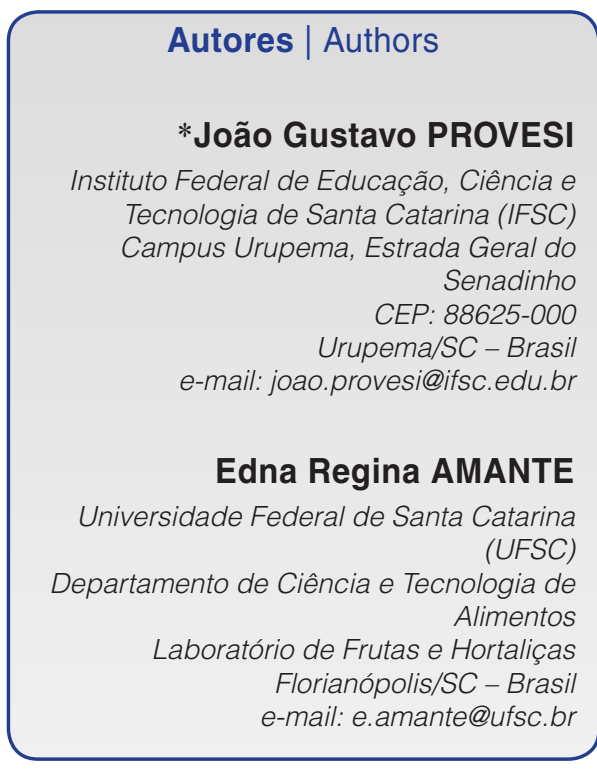

*Autor Correspondente / Corresponding Author

Recebido: Dez. 17, 2014

Aprovado: Maio 12, 2015

\section{Resumo}

Um dos métodos mais tradicionais na conservação de alimentos, o congelamento também pode alterar de forma significativa as características do produto. Grandes cristais de gelo provocam alteração na textura e/ou danos a membranas e componentes celulares. As técnicas de congelamento rápido formam cristais de gelo menores do que o processo lento, porém as flutuações de temperatura durante a distribuição e transporte podem promover o crescimento dos cristais. Esse processo é conhecido como recristalização e é uma barreira na utilização do congelamento como método de conservação em muitos casos. O uso de crioprotetores tradicionais, como a sacarose, é uma alternativa limitada, uma vez que concentrações elevadas são requeridas. Na década de 1970, foi descrita em peixes de águas frias uma classe de proteínas que, em baixa concentração, pode interagir e influenciar o crescimento do cristal de gelo. Elas foram chamadas de proteínas anticongelantes (PACs), sendo encontradas também em plantas, animais e micro-organismos ambientados a baixas temperaturas. Essas proteínas podem intervir no processo de formação do núcleo inicial do gelo, reduzir o ponto de congelamento da água, ou, ainda, inibir a recristalização, principalmente para PACs de vegetais. Há diversos trabalhos publicados e algumas patentes registradas para o uso de PACs em diversos alimentos, como lácteos, carnes, massas, frutas e hortaliças, conservando de melhor forma as características originais do alimento. Atualmente, o custo ainda é uma barreira para utilização comercial das PACs. Contudo, a descoberta de novas fontes pode reduzir seu custo e tornar essas proteínas uma ferramenta efetiva na manutenção da textura de alimentos congelados. Baseada em trabalhos que avaliaram aspectos químicos das PACs e exemplos de sua aplicação, esta revisão tem como objetivo principal apresentar as características gerais das PACs e discutir sobre sua utilização.

Palavras-chave: Proteínas anticongelantes; Gelo; Congelamento; Recristalização.

\section{Summary}

Although freezing is one of the traditional methods of food preservation, it can also significantly change the product characteristics. Large ice crystals cause changes in the texture and damage cell membranes and components. The quick freezing techniques form smaller ice crystals than the slow process, but temperature fluctuations during transport and distribution can promote crystal growth. This process is known as recrystallization and is a barrier to the use of freezing as a preservation method in many cases. The use of traditional cryoprotectants such as sucrose is a limited alternative since high concentrations are required. In the 70's a cold water fish class of proteins was described that could interact and influence ice crystal growth even at low concentrations. They were denominated antifreeze proteins (AFPs) and are also found in plants, animals and microorganisms acclimatized to low temperatures. These proteins can interfere in the formation of the initial stable ice crystal nucleus, reduce the freezing point of water, or even inhibit the recrystallization process, especially in the case of plant AFPs. Several papers have been published and some patents registered on the use of antifreeze proteins in several foods such as dairy and meat products, pasta, fruits and vegetables, preserving the original characteristics of the products in a better way. Currently the cost is still a barrier to the commercial use of AFPs but 
the discovery of alternative sources could reduce the costs and make them an effective tool in the maintenance of the texture of frozen foods. Based on studies that evaluated the chemical aspects of antifreeze proteins and examples of their application, this review aims to present the general characteristics of AFPs and discuss their use.

\section{Key words: Freezing proteins; Ice; Freezing; Recrystallization.}

\section{Introdução}

O congelamento é um dos métodos mais antigos e tradicionais utilizado pelo homem para conservação de alimentos. Atualmente, mesmo com uma cadeia logística que torna seu custo mais elevado frente a outros métodos de conservação, os alimentos congelados ainda possuem um amplo mercado, principalmente devido à sua praticidade de consumo.

Contudo, se, por um lado, as baixas temperaturas e a formação dos cristais de gelo reduzem o crescimento de micro-organismos e a atividade enzimática, por outro, quando grandes cristais de gelo são formados, pode ocorrer danos à integridade de componentes celulares, alterando de forma significativa as características originais do alimento. Sem dúvida, a taxa ou velocidade de congelamento é um aspecto importante, uma vez que leva à formação de cristais de gelo menores e, consequentemente, menores os impactos sobre a qualidade do produto. Ainda assim, é preciso considerar que o crescimento dos cristais de gelo é um processo dinâmico, que se mantém mesmo durante o armazenamento em baixas temperaturas.

A possibilidade de exercer um controle sobre o comportamento do gelo após a sua formação sempre foi um desafio para pesquisadores de diversas áreas. O uso de aditivos crioprotetores é facilmente encontrado na literatura, porém normalmente é necessário que essas substâncias estejam presentes em concentrações elevadas, o que inviabiliza seu emprego na maior parte dos alimentos.

Efetivas mesmo em baixas concentrações, uma classe de proteínas descritas, inicialmente, em peixes de águas frias surgiu como uma alternativa para a área de Ciência e Tecnologia de Alimentos, demonstrando a propriedade de influenciar o crescimento do cristal de gelo e o seu crescimento em alimentos congelados. Essas proteínas foram chamadas de proteínas anticongelantes (PACs) e, posteriormente, descritas também em plantas, animais, fungos e bactérias que vivem em ambientes de baixas temperaturas. Embora ainda em pequeno número, já existem alguns trabalhos envolvendo o uso das PACs em produtos lácteos, carnes, massas e vegetais, com resultados promissores, conforme será apresentado no decorrer deste trabalho. Também já foram registradas patentes com esse mesmo prospecto.
Sendo assim, considerando a relevância do tema e o caráter de inovação dessa emergente tecnologia, este trabalho tem como objetivo apresentar diferentes aspectos das PACs, como estrutura, fontes e mecanismo de ação, bem como discutir a sua aplicabilidade como aditivo da indústria alimentícia.

\section{2 Água e gelo}

Uma das substâncias mais abundantes do nosso planeta, a água apresenta uma importância primordial para qualquer forma de vida, participando ou servindo como meio para diversas reações químicas que ocorrem em nível celular. Sua molécula não possui diretamente uma carga positiva ou negativa, contudo as ligações entre seus hidrogênios e o átomo de oxigênio conferem a ela um caráter essencialmente polar. Essa característica possibilita o alinhamento espontâneo de diversas moléculas de água, por meio de interações do tipo ligação de hidrogênio, refletindo na coesão da água no estado líquido (WHATEN e JIA, 2005).

Em um sistema com energia reduzida, cada molécula de água forma quatro ligações de hidrogênio com moléculas mais próximas, em um arranjo de conformação tetraédrica. Sem energia para romper essas ligações, a água assume sua forma sólida. A forma hexagonal do cristal de gelo é a única estável a pressão atmosférica normal e temperaturas entre 0 e $-60^{\circ} \mathrm{C}$. Nessa forma, os cristais de gelo possuem três eixos $a$, crescendo em um plano basal, e outro eixo $c$, crescendo em um plano prismático, perpendicular ao plano basal (Figura 1) (GRIFFITH e EWART, 1995).

Os dois planos possuem taxas de crescimento distintas, sendo que as do plano prismático acontece de forma muito mais rápida do que as do plano basal. A temperatura é um fator chave na velocidade e na forma de crescimento dos cristais de gelo. Tanto que, em temperaturas logo abaixo de $0^{\circ} \mathrm{C}$, os cristais têm uma morfologia circular, como discos, e, em temperaturas ainda menores, como $-10{ }^{\circ} \mathrm{C}$, eles possuem uma forma mais irregular, como agulhas (HASSAS ROUDSARI e GOFF, 2012).

É interessante observar que, embora se considere $0{ }^{\circ} \mathrm{C}$ como o ponto de congelamento da água, isso não quer dizer que ao atingir essa temperatura a água, necessariamente, iniciará o processo de solidificação. 


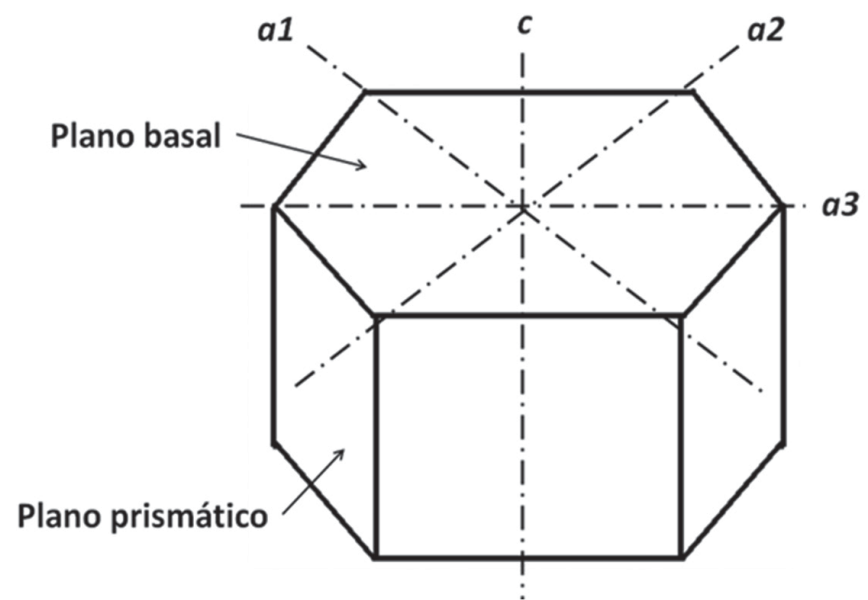

Figura 1. Morfologia de um cristal de gelo: três eixos a, crescendo em um plano basal, e um eixo $c$, crescendo em um plano prismático. Fonte: Adaptado de Griffith e Ewart (1995).

Quando a água ou qualquer outro líquido é resfriado, os movimentos das moléculas diminuem, mas a solução pode permanecer na fase líquida mesmo com a temperatura inferior ao ponto de congelamento. Esse estado é conhecido como sobrearrefecimento ou, no termo utilizado na língua inglesa, supercooling state (GOFF, 2005). Isso é possível porque a formação do gelo, ou cristalização, ocorre em duas etapas.

A etapa inicial é a nucleação, na qual ocorre a formação de um pequeno cristal de gelo inicial que, como o nome da etapa já sugere, servirá como um núcleo para a propagação do cristal, que é a segunda etapa do processo. Como a nucleação não é uma etapa energeticamente favorável, o processo não se inicia de modo espontâneo na faixa de temperatura logo abaixo a $0{ }^{\circ} \mathrm{C}$. O mais comum é a ocorrência de uma nucleação heterogênea, com a presença de uma molécula externa servindo como núcleo. A nucleação homogênea, de forma espontânea, ocorre somente em baixas temperaturas, como no caso da água ultrapura. Após a formação do núcleo inicial, o crescimento do cristal de gelo ocorre espontaneamente em temperaturas pouco abaixo de $0{ }^{\circ} \mathrm{C}$ (WHATEN e JIA, 2005).

Se o calor for removido de uma forma mais rápida, há formação de um maior número de núcleos, mais estáveis, o que reflete em um número maior de cristais, com tamanho reduzido. Uma taxa mais lenta de retirada de calor leva à formação de um menor número de cristais, mas com maior tamanho (GOFF, 2005).

Em uma fase posterior, após a formação dos cristais, é possível ainda a ocorrência do processo de recristalização, que corresponde à reestruturação dos cristais de gelo nas variações de temperatura na faixa abaixo de zero, levando sempre à formação de cristais maiores (GRIFFITH e EWART, 1995; CRUZ et al., 2009).
Diversos mecanismos são propostos para o processo de recristalização, como a conversão de cristais de superfície irregular nos de superfície lisa, mais estáveis; ou a fusão entre dois cristais vizinhos, resultando em outros maiores; ou, ainda, um processo de migração de moléculas de água entre cristais, formando-os em tamanho maior às custas da redução ou desaparecimento dos menores. Nesse caso, a variação de temperatura leva à fusão parcial de cristais pequenos, mais instáveis devido à sua alta energia de superfície, e as moléculas de água livres tendem a se depositar nos cristais grandes, aumentando seu tamanho. Todos esses mecanismos acontecem de forma simultânea e em diferentes graus no sistema, diminuindo o número de cristais, mas aumentando o tamanho médio (HASSAS ROUDSARI e GOFF, 2012).

Levando esse cenário para a água presente em organelas, células ou tecidos, quanto maior o cristal de gelo formado, maior a possibilidade de dano físico a membranas biológicas. Por isso o processo de recristalização é sempre uma preocupação, em áreas que veem no congelamento uma alternativa de método de conservação, como é o caso da criopreservação de órgãos e tecidos na área médica, do congelamento de sementes e espécies vegetais na agricultura e também no congelamento de produtos alimentícios na área de Ciência e Tecnologia de Alimentos.

\section{Proteínas anticongelantes (PACs)}

Apesar do cenário desfavorável que a formação de gelo dentro da célula pode causar a qualquer forma de vida, existem inúmeros exemplos de seres vivos que têm seu habitat em ambientes de frio intenso, com temperaturas inferiores ao ponto de congelamento da água. Os peixes e os outros seres marinhos que habitam as águas dos oceanos Ártico e Antártico, por exemplo, convivem com temperaturas que chegam a $-2{ }^{\circ} \mathrm{C}$. Também existem diversas espécies de insetos e de vegetais que sobrevivem a invernos rigorosos em diferentes partes do planeta.

Esses seres desenvolveram ao longo de sua evolução uma série de mecanismos que permitem sua sobrevivência a esse tipo de ambiente. Uma das estratégias possíveis envolvendo a tolerância ao congelamento, adotada por alguns desses organismos, é a liberação ativa de nucleadores para o espaço extracelular, promovendo o congelamento fora da célula. A pressão osmótica resultante atrai a água também para o meio extracelular, o que leva a uma redução do ponto de congelamento dentro da célula. Isso é possível para algumas espécies que possuem elevados níveis de crioprotetores, como glicerol ou glicose (WHATEN e JIA, 2005).

Há ainda organismos que conseguem manter seus fluidos corporais em um estado de sobrearrefecimento, 
por meio de mecanismos que impedem o processo de nucleação. Em baixas temperaturas, eles cessam a produção de potenciais substâncias nucleadoras e eliminam aquelas ingeridas durante a alimentação. Além disso, protegem a abertura de poros que serviriam de entrada para nucleadores (WHATEN e JIA, 2005; BILDANOVA et al., 2013).

Em muitos casos, contudo, essas estratégias por si só não seriam suficientes para garantir a sobrevivência desses seres em ambientes de frio tão intenso. Em meados da década de 1970, foi descoberta em peixes de águas frias uma classe de proteínas com a capacidade de influenciar o crescimento de cristais de gelo por meio da interação com a sua superfície. Devido a essa propriedade, foram denominadas proteínas anticongelantes (PACs). Posteriormente, proteínas de tamanhos e estrutura variadas, mas com a mesma propriedade, também foram encontradas e descritas em vegetais, insetos, fungos e bactérias, sempre em espécies e variedades expostas a baixas temperaturas (EWART et al., 1999; CAl et al., 2011).

Há basicamente três formas de interação entre as PACs e os cristais de gelo. A primeira é por meio da interferência no processo de nucleação, que ocorre pela ligação de algumas PACs a substâncias nucleadoras, impedindo o início do processo de formação do gelo (GRIFFITH e EWART, 1995; HASSAS ROUDSARI e GOFF, 2012). A segunda forma é por intermédio da redução da temperatura de congelamento de líquidos corporais por uma via não coligativa, sem alterar significativamente o ponto de fusão, em uma propriedade conhecida como histerese térmica (PUDNEY et al., 2003; QIU et al., 2013). Algumas PACs, por exemplo, provocaram a redução do ponto de congelamento da água em até $3^{\circ} \mathrm{C}$. Esse efeito normalmente está ligado a uma maior concentração dessas substâncias (GRIFFITH e YAISH, 2004).

Outro grupo de PACs, entretanto, possui a interessante capacidade de inibir o processo de recristalização. Essa propriedade não depende de elevadas concentrações de proteínas na matriz, com efetiva inibição da recristalização em concentrações menores do que $100 \mu \mathrm{g} / \mathrm{L}$. É interessante destacar que as PACs de plantas se mostram ainda mais efetivas na inibição da recristalização do que proteínas de insetos e de peixes, com ação a partir de 25 g/L (ZHANG et al., 2004).

Embora ainda não tenham sido completamente elucidadas as bases químicas para o mecanismo de ação das PACs na inibição da recristalização, é certo que seus efeitos ocorrem devido à adsorção dessas proteínas a diferentes partes da superfície do cristal de gelo, em locais específicos, por uma ou mais forma de interações, como ligações de hidrogênio ou forças de Van der Waals (CRUZ et al., 2009). O crescimento do cristal continua em menor grau nas regiões sem proteínas. Mas, em um segundo momento, a alteração na curvatura da superfície do cristal, provocada por esse crescimento irregular, leva à relação área superficial/volume muito além do ponto em que seria termodinamicamente favorável para o crescimento do gelo, o que o faz cessar. Esse mecanismo é conhecido como Efeito de Kelvin (Gibbs-Thomson), sendo o mais utilizado para explicar o mecanismo geral de ação das PACs, embora apresente limitações em alguns casos (FEENEY e YEH, 1998; KONTOGIORGOS et al., 2008).

Assim, enquanto que na ausência dessas proteínas o crescimento do cristal de gelo ao longo do eixo a resulta em uma expansão do plano basal, na presença das PACs o crescimento ocorre predominantemente ao longo do eixo $c$, dando origem a um prisma de faces perpendiculares. A morfologia do cristal resultante é similar a pirâmides hexagonais ou agulhas (Figura 2).

Não é consenso se as ligações entre as PACs e os cristais são reversíveis ou não. Alguns autores defendem a ideia de que a ligação precisaria ser irreversível para que a inibição pudesse ocorrer, enquanto outros pesquisadores alegam que uma ligação irreversível causaria um estado de "superaquecimento", e, assim, os cristais de gelo seriam estáveis durante horas em temperaturas acima do seu ponto de fusão, o que não é observado (HASSAS ROUDSARI e GOFF, 2012).

É certo apenas que ainda restam muitos detalhes sobre os mecanismos de ação das PACs a serem desvendados. Vários estudos foram realizados com a finalidade de esclarecer melhor a estrutura, o mecanismo

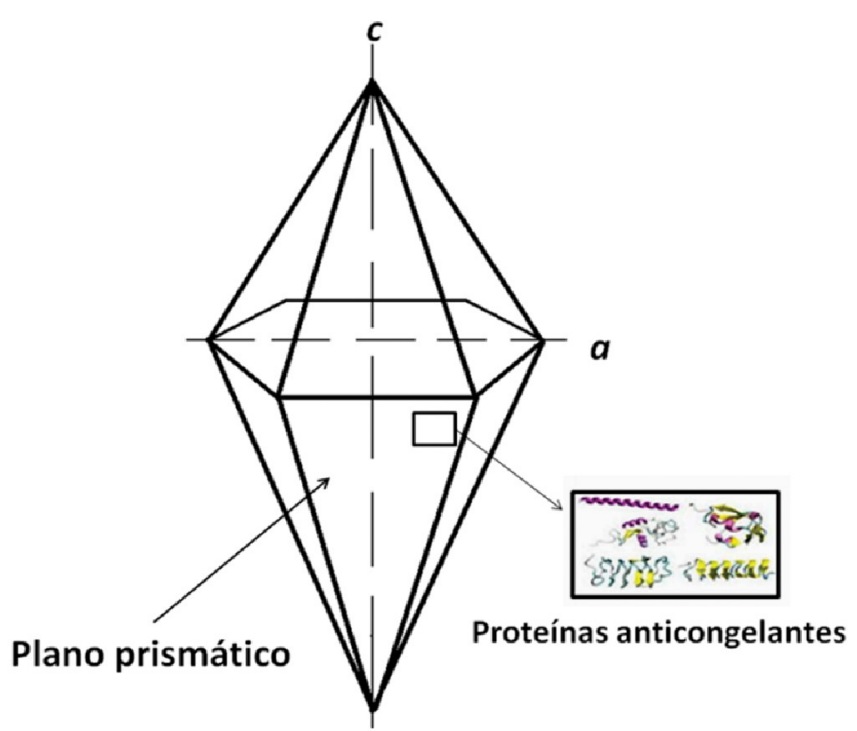

Figura 2. Morfologia do cristal de gelo em uma solução contendo proteínas anticongelantes: crescimento preferencial ao longo do eixo C, assumindo uma forma bipiramidal. Fonte: Adaptado de Griffith e Ewart (1995) e Hassas Roudsari e Goff (2012). 
de ação e a relação desses mecanismos nas PACs de peixes, insetos e plantas (BAARDSNES et al., 1999; MADURA e WIERZBICKI, 1999; ANTSON et al., 2001; TSVETKOVA et al., 2002; PUDNEY et al., 2003; LIU et al., 2005; SALVAY et al., 2010; MIDDLETON et al., 2012). Porém essa não é uma tarefa simples, ainda mais considerando a quantidade de estruturas diferentes encontradas nas diversas espécies e variedades estudadas, criando inúmeras e complexas interações. Uma abordagem mais detalhada sobre o mecanismo de ação das PACs, relacionando estrutura da proteína com os diferentes tipos de atividade anticongelantes, pode ser encontrada na revisão realizada por Davies (2014).

As diferentes PACs glicosiladas, ligadas a uma molécula de açúcar, encontradas em peixes possuem tamanho semelhante e têm como característica as várias repetições do tripeptídeo Ala-Ala-Thr, além da presença de moléculas do dissacarídeo galactose-N-acetilgalactosamina. Já as PACs não glicosiladas dessas espécies são subdivididas em quatro grupos, sequencialmente numeradas na ordem que foram descobertas (I, II, III, IV), variando em relação ao tamanho, composição e fonte (BAARDSNES et al., 1999). A PAC tipo I é mais frequentemente encontrada em linguados e são ricas em alanina (Ala). A PAC tipo II também tem sua composição majoritária de Ala, mas possui uma quantidade de cisteína (Cys) e alguns aminoácidos aromáticos (Phe, Trp e Tir). No tipo III, descrita em peixe-carneiro, não há predominância de aminoácidos, tendo uma estrutura mais balanceada. A última PAC descoberta, tipo IV, em peixe-escorpião tem a estrutura altamente helicoidal e bem diferente das outras, com predominância de glutamina (Gln) e ácido glutâmico (Glu) (LILLFORD e HOLT, 1994; VIEIRA, 2011).

As PACs também já foram descritas em vários artrópodes, como aranhas, ácaros, gafanhotos e mais de 50 espécies de insetos (DUMAN et al., 2004; BILDANOVA et al., 2013). As PACs encontradas em insetos são de 10 a 100 vezes mais ativas do que as proteínas de peixes, provavelmente devido às temperaturas mais extremas enfrentadas no meio terrestre. Além disso, elas possuem menos açúcares e um percentual mais alto de aminoácidos hidrofílicos (GRIFFITH e EWART, 1995; WHARTON et al., 2009). Qiu et al. (2013) relataram que, curiosamente, proteínas com propriedades anticongelantes também foram encontradas em situações de calor acentuado, como no besouro do deserto (Microdera punctipennis), possivelmente como mecanismo da espécie para conservação da água nessas condições.

Ao projetar a aplicação prática das PACs, é preciso, porém, pensar em uma fonte abundante dessas moléculas, para que o custo de obtenção não seja elevado e inviabilize sua utilização. Nesse sentido, as
PACs de vegetais têm merecido grande atenção, uma vez que sua presença já foi relatada em diversas espécies de inverno, expostas e tolerantes a baixas temperaturas, além de apresentarem uma capacidade de inibir o processo de recristalização superior às proteínas de peixes e de insetos.

\subsection{PACs em vegetais}

No início da década de 1990, Griffith et al. (1992) descreveram de forma pioneira a presença de PACs em vegetais, em um trabalho com folhas de centeio (Secale cereale) de variedade de inverno. Atualmente, já foi relatada a presença de PACs em diversas espécies vegetais, como trigo, centeio, cenoura, azevém, canola, entre tantas outras, abrangendo gimnospermas e angiospermas, mono e dicotiledôneas (Tabela 1) (GRIFFITH e EWART, 1995; GRIFFITH e YAISH, 2004). As PACs foram descritas em diferentes partes desses vegetais, como sementes, talos, nós, córtex, pecíolos, folhas, flores, frutos, raízes, rizomas e tubérculos (BILDANOVA et al., 2013), sendo localizadas, principalmente, nos espaços intercelulares, conhecidos como apoplasto (JARZABEK et al., 2009).

De um modo geral, as PACs em vegetais são peptídeos de tamanho pequeno, com baixo peso molecular. Em estudos com extratos de variedades de centeio de inverno, Hon et al. (1994) encontraram cinco PACs em uma faixa entre 19 a $36 \mathrm{kDa}$. Smallwood et al. (1999) relataram a presença predominante de uma PAC de peso molecular de $36 \mathrm{kDa}$ em cenouras (Daucus carota). Huang e Duman (2002) isolaram três PACs das folhas da espécie Solanum dulcamara com pesos moleculares de 67, 47 e 29 kDa. Hassas Roudsari (2011) descreveu a presença de PACs de tamanhos entre 14 a $43 \mathrm{kDa}$ em extratos de folhas de trigo de variedade de inverno (Triticum aestivum cv. Vienna). Ding et al. (2015) relataram uma maior concentração de proteínas entre 31 e 43 $\mathrm{kDa}$ em amostras de cevada. Sidebottom et al. (2000) analisaram a principal PAC presente em amostras de azevém (Lolium perenne), chegando a um peptídeo de aproximadamente $12 \mathrm{kD}$, composto por 118 aminoácidos, rico em aspargina (25\%), valina (16\%), serina (15\%) e treonina (10\%).

Um ponto interessante é que diversas dessas PACs descritas foram identificadas como isoformas de classes de proteínas relacionadas a respostas da planta contra patogenias vegetais, como quitinases, -1,3-glucanase e taumatina. Apesar da composição semelhante, nem sempre elas apresentaram a mesma atividade presente nas proteínas de defesa (ATICI e NALBANTOGLU, 2003; GRIFFITH e YAISH, 2004).

As PACs são encontradas somente em variedades vegetais de inverno, expostas e tolerantes às baixas temperaturas. O estado de frio, ou, ainda, a desidratação 
Revisão: Proteínas anticongelantes - uma tecnologia emergente para o congelamento de alimentos

PROVESI, J. G. e AMANTE, E. R.

Tabela 1. Trabalhos envolvendo a presença de proteínas anticongelantes em plantas.

\begin{tabular}{|c|c|c|}
\hline Espécie & Nome comum & Autor \\
\hline \multirow{2}{*}{ Ammopiptanthus mongolicus } & \multirow{2}{*}{-} & Yong et al. (2000) \\
\hline & & Wang e Wei (2003) \\
\hline Avena sativa & Aveia (folha) & Antikainen e Griffith (1997) \\
\hline \multirow{7}{*}{ Daucus carota } & \multirow{7}{*}{ Cenoura } & Worrall et al. (1998) \\
\hline & & Smallwood et al. (1999) \\
\hline & & Meyer et al. (1999) \\
\hline & & Wang et al. (2002) \\
\hline & & Zhang et al. (2004) \\
\hline & & Gomez Galindo et al. (2005) \\
\hline & & Ding et al. (2014) \\
\hline Forsythia suspensa & Forsythia & Simpson et al. (2005) \\
\hline \multirow{2}{*}{ Hordeum vulgare } & \multirow{2}{*}{ Cevada (folha) } & Antikainen e Griffith (1997) \\
\hline & & Ding et al. (2015) \\
\hline \multirow{4}{*}{ Lollium perene } & \multirow{4}{*}{ Azevém } & Pudney et al. (2003) \\
\hline & & Sidebottom et al. (2000) \\
\hline & & Lauersen et al. (2011) \\
\hline & & Middleton et al. (2012) \\
\hline Picea abies e Picea pungens & $\begin{array}{l}\text { Pícea europeia e Pícea } \\
\text { azul }\end{array}$ & Jarzabek et al. (2009) \\
\hline Prunus persica & Pêssego (caules) & Wisniewski et al. (1999) \\
\hline \multirow{7}{*}{ Secale cereale } & \multirow{7}{*}{ Centeio (folha) } & Griffith et al. (1992) \\
\hline & & Marentes et al. (1993) \\
\hline & & Hon et al. (1994) \\
\hline & & Antikainen e Griffith (1997) \\
\hline & & Griffith et al. (1997) \\
\hline & & Vieira (2011) \\
\hline & & Lim et al. (2013) \\
\hline \multirow{3}{*}{ Solanum dulcamara } & \multirow{3}{*}{ Dulcamara (folha) } & Urrutia et al. (1992) \\
\hline & & Duman (1994) \\
\hline & & Huang e Duman (2002) \\
\hline \multirow[t]{2}{*}{ Solanum tuberosum } & Batata (folha) & Urrutia et al. (1992) \\
\hline & & Antikainen e Griffith (1997) \\
\hline \multirow[t]{2}{*}{ Triticum aestivum } & Trigo (folha) & Zhang et al. (2007a) \\
\hline & & Vieira (2011) \\
\hline
\end{tabular}

causada por ele, constitui um sinal que induz a expressão dessas proteínas (ATICI e NALBANTOGLU, 2003; HASSAS ROUDSARI e GOFF, 2012). Assim, é necessário um período de aclimatação ao frio para que essas proteínas sejam expressas (BILDANOVA et al., 2013). Esse processo ocorre durante o outono ou nas primeiras semanas de inverno. Com a chegada da primavera, ocorre a desaclimatação, ou seja, sua tolerância ao frio volta a cair (JARZABEK et al., 2009). Embora existam outras condições ambientais que influenciem a aclimatação, como iluminação, quantidade de água, nutrição e presença de doenças, a temperatura é sem dúvida o principal fator na indução da resposta vegetal e expressão das PACs (GÓMEZ GALINDO et al., 2005).

Ainda não são conhecidos todos os detalhes de como ocorre essa transmissão de sinais, entre a percepção do frio pela planta até a expressão das proteínas. É certo que o cátion $\mathrm{Ca}^{2+}$ desempenha um importante papel entre a percepção da temperatura e a transdução do sinal; além disso, também é provável 
a ação de substâncias como etileno e ácido abscísico (ABA). Em algumas espécies, os níveis máximos de PACs são atingidos após alguns dias de exposição ao frio, enquanto em outros podem chegar a um máximo após quatro ou cinco semanas (BILDANOVA et al., 2013).

Gómez Galindo et al. (2005) acompanharam o efeito da temperatura na concentração de PACs em cenouras durante o cultivo em dois anos diferentes. No primeiro ano, no qual foram registrados diversos dias com temperaturas inferiores a $6{ }^{\circ} \mathrm{C}$, as concentrações de PACs foram superiores quando comparadas as cenouras cultivadas no segundo ano, no qual as temperaturas mínimas diárias foram mais altas, raramente ultrapassando $6^{\circ} \mathrm{C}$. Os autores ressaltam ainda que os vegetais do primeiro ano mantiveram, de forma mais satisfatória, sua qualidade durante o armazenamento em temperaturas de refrigeração do que as cenouras do segundo ano.

Em relação ao tipo de ação das PACs de vegetais, a atividade de histerese térmica observada nesse grupo normalmente é bastante baixa ou insignificante. Enquanto em PACs de insetos esse valor pode variar entre 3 a $5{ }^{\circ} \mathrm{C}$, nas proteínas encontradas em plantas normalmente se encontram na faixa de 0,1 a $0,6^{\circ} \mathrm{C}$ (GRIFFITH e YAISH, 2004). Por exemplo, a histerese térmica observada em proteínas no extrato apoplástico de folhas de trigo da variedade de inverno variou de 0,4 a 0,6 ${ }^{\circ} \mathrm{C}$ (HASSAS ROUDSARI, 2011).

No entanto, as PACs de vegetais se destacam pela ação de inibição do processo de recristalização, mesmo em baixas concentrações $(<25 \mu \mathrm{g} / \mathrm{L})$. Isso ocorre, possivelmente, porque essas proteínas interagem com os cristais de gelo em múltiplos locais (GRIFFITH e YAISH, 2004). As PACs extraídas da espécie Lolium perenne, por exemplo, demonstraram uma forte inibição do crescimento de cristais de gelo em soluções de $30 \%$ de sacarose, em concentrações inferiores a $10 \mu \mathrm{g} / \mathrm{mL}$, o que é cerca de 200 vezes menor do que a concentração necessária para que a proteína tipo III encontrada em peixe-carneiro (Macrozoarces americanus) tenha o mesmo efeito (SIDEBOTTOM et al., 2000). Por serem concentrações normalmente insignificantes para provocar alterações sensoriais em produtos alimentícios, elas despontam como uma alternativa interessante para minimizar os impactos sobre a textura após o descongelamento e para expandir a vida de prateleira de produtos congelados.

\section{Uso das PACs na área de Tecnologia de Alimentos}

O congelamento é um método bem-sucedido para a preservação por longo tempo dos atributos naturais de qualidade de alimentos perecíveis. Entretanto, para produtos formados por células, como carnes e vegetais, os cristais de gelo que são formados podem também causar considerável perda por exsudação, perda de textura, cor e modificações sensoriais após descongelamento (TALENS et al., 2003; VELICKOVA et al., 2013).

Embora ainda em pequeno número, diversos estudos têm apontado a possibilidade da aplicação das PACs na preservação da qualidade sensorial e nutricional de alimentos durante o processamento e o armazenamento; isso considerando concentrações cerca de 300 a 500 vezes menores do que as de outras substâncias crioprotetoras, como a sacarose e o sorbitol (BILDANOVA et al., 2013).

Em alimentos consumidos ainda congelados, como sorvetes e sobremesas lácteas, o processo de recristalização durante o armazenamento pode provocar importante alteração sensorial, com crescimento dos cristais de gelo (WHATEN e JIA, 2005). Feeney e Yeh (1998) relataram o crescimento de cristais de gelo em amostras controle após 1 hora de armazenamento a -6 e $-8^{\circ} \mathrm{C}$, enquanto que, em amostras contendo PACs, esse crescimento não existiu. Gaukel et al. (2014) utilizaram soluções de sacarose como modelo simplificado para sorvetes, relatando efeitos sinérgicos para inibição da recristalização nessas amostras com misturas de PACs diferentes, ou, ainda, de PACs com outros coloides, como alginato de sódio e k-carragena. Nesse tipo de produtos, inclusive já foram registradas patentes para a utilização de alguns tipos de PACs (CLEMMINGS et al., 1997; UNILEVER, 2001).

Payne et al. (1994) verificaram que baixas concentrações de PACs reduziram os danos causados pelo congelamento de carnes, conservando de melhor forma as características do produto original. A adição de PACs à carne de cordeiro também apresentou a formação de cristais de gelo menores, com consequente redução na perda de líquido no descongelamento (PAYNE e YOUNG, 1995). Amostras de carne congeladas tratadas com PAC produzida por Lactococcus lactis demonstraram menor gotejamento e perda de proteína no descongelamento, com consequente melhora na avaliação sensorial (YEH et al., 2009). Boonsupthip e Lee (2003) também relataram a funcionalidade do uso das PACs na conservação de géis formados com proteínas da carne em condições de congelamento, tendo um desempenho melhor do que o crioprotetor formado por uma mistura de sacarose e de sorbitol.

O congelamento também seria uma alternativa para aumentar a curta vida de prateleira de massas frescas, se isso não causasse diversos problemas tecnológicos. A adição de um extrato proteico concentrado obtido de cenouras aumentou significativamente a capacidade de fermentação de massas congeladas, bem como o volume do pão obtido ao final, sem nenhum prejuízo em relação à textura ou a outro aspecto da qualidade sensorial (ZHANG et al., 2007b; ZHANG et al., 2008). 
Ding et al. (2014) avaliaram o efeito da adição de PACs extraídas de cenouras sob diversas propriedades termofísicas, de textura, de cozimento e na microestrutura de noodles congelados. Os resultados obtidos após a análise de calorimetria exploratória diferencial (DSC) demonstraram que a presença das PACs reduziu o conteúdo de água congelável na amostra. Além disso, melhoraram as propriedades de textura e de cozimento dos noodles. As imagens obtidas por microscopia eletrônica sugerem que o efeito das proteínas sobre a formação dos cristais de gelo protege a rede do glúten de danos causados pelo congelamento e pela flutuação de temperatura durante a estocagem sob congelamento. A adição de 0,5\% (m/m) de PACs em géis de amido de milho e trigo também aumentou a estabilidade durante o congelamento (LI et al., 2010).

As frutas e as hortaliças também teriam no congelamento uma opção interessante para sua conservação, sobretudo em pedaços prontos para o consumo, uma vez que o consumidor busca alimentos mais saudáveis e práticos, mas sem abdicar da qualidade sensorial. Nesse tipo de alimento, o congelamento normalmente provoca alterações importantes, como amolecimento do tecido vegetal e excessiva perda de líquido.

Velickova et al. (2013) avaliaram o efeito da infusão de crioprotetores, como a trealose, extrato de trigo-grama (PACs) ou a mistura de ambos, na qualidade de morangos congelados. A perda de líquido em amostras tratadas com crioprotetores foi significativamente menor do que em amostras controle. Isso refletiu também em uma menor alteração na textura dos morangos após o descongelamento. Embora o uso conjunto seja uma possibilidade, é importante destacar que esse efeito foi observado para o extrato vegetal mesmo em baixas concentrações.

No trabalho realizado por Cruz et al. (2009), também foi observada uma menor alteração na textura de agriões congelados, tratados previamente com uma solução de PACs do tipo I (peixes), quando comparadas a amostras controle. A amostra tratada com a PAC apresentou também uma coloração mais uniforme após o descongelamento.

A avaliação do efeito das PACs em determinado alimento se inicia com a difícil tarefa da seleção da proteína a ser utilizada. Diversos tipos de proteínas estão disponíveis em peixes, insetos, plantas e bactérias. Algumas proteínas possuem características que podem beneficiar ou limitar seu uso em determinado tipo de alimento. A PAC tipo I, extraída de peixes, não é estável em temperaturas próximas a $20^{\circ} \mathrm{C}$; logo não pode ser utilizada em produtos que são aquecidos antes do congelamento. Já a PAC extraída de variedades de centeio de inverno é similar a taumatina, uma proteína com poder adoçante. Por isso o uso desse tipo de proteína está limitado a produtos que normalmente são adoçados durante a preparação (GRIFFITH e EWART, 1995).

A elaboração de peptídeos com propriedade anticongelante, obtidos a partir da hidrólise de proteínas, também é uma opção emergente. Wang et al. (2014), por exemplo, avaliaram peptídeos obtidos a partir da hidrólise de colágeno de pele de tubarão como protetores ao congelamento de Lactobacillus bulgaricus, amplamente utilizado em produtos fermentados. A taxa de sobrevivência do L. bulgaricus na amostra controle, com água esterilizada, foi de apenas 0,44\%, aumentando para $12,4 \%$ para a hidrolisado bruto e para mais de $90 \%$ após as etapas de purificação desses peptídeos, sempre em concentrações de $250 \mu \mathrm{g} / \mathrm{mL}$.

Ainda é possível a utilização de combinações de diferentes proteínas, com efeitos complementares, para se alcançar um melhor resultado na conservação.

O próximo ponto é a inserção da proteína à matriz alimentar. Para alimentos que produzem naturalmente essas proteínas, a questão se limita ao estímulo na sua produção. Para outros alimentos, a adição pode se dar por diferentes métodos físicos, como mistura, injeção, imersão, revestimento, pulverização ou impregnação a vácuo, dependendo do alimento em questão (HASSAS ROUDSARI e GOFF, 2012). Para proteger tecidos vegetais do congelamento, por exemplo, é crucial que as PACs alcancem o apoplasto, uma vez que o gelo se forma preferencialmente nesse local (CRUZ et al., 2009).

A modificação genética pela introdução de genes de expressão das PACs também é avaliada. Em modelos de plantas transgênicas de tabaco, a inserção do gene de uma PAC de 36 kD de cenouras aumentou a tolerância dessa espécie ao frio (WEN-LI et al., 2005). Naturalmente que essa não é uma tarefa das mais fáceis, pois envolve uma série de fatores no material transgênico obtido e há diversos pontos a serem ainda investigados para essa possibilidade (WHATEN e JIA, 2005). Uma revisão mais detalhada sobre o assunto, envolvendo a transformação com diferentes genes de peixes, insetos e plantas, pode ser encontrada no trabalho de Duman e Wisniewski (2014).

Em relação à toxicidade e à segurança de consumo das PACs em outras matrizes alimentares, vale lembrar que elas já são rotineiramente consumidas na dieta humana, uma vez que são encontradas em várias plantas e peixes de água fria (CREVEL et al., 2002). Estudos realizados in vitro demonstraram ausência de toxicidade em concentrações maiores que $5 \mu \mathrm{g} / \mathrm{mL}$, superiores às necessárias para se obter o efeito de inibição da recristalização (WANG et al., 2002).

\section{Conclusões e perspectivas futuras}

As PACs podem, em um futuro não tão distante, representar uma ferramenta importante de controle sobre o crescimento do cristal de gelo, propriedade que interessa a diversas áreas científicas e tecnológicas. 
Revisão: Proteínas anticongelantes - uma tecnologia emergente para o congelamento de alimentos

PROVESI, J. G. e AMANTE, E. R.

Apesar de inúmeros estudos acerca de seus aspectos químicos, é certo que ainda restam muitos detalhes sobre os mecanismos de ação das PACs a serem desvendados. A maior dificuldade para obter uma explicação mais detalhada é a impossibilidade de se visualizar diretamente as interações moleculares entre as PACs e o gelo, uma vez que o complexo é instável até mesmo em técnicas como a cristalografia de raios $X$ e a ressonância magnética nuclear (NMR). Pesquisas utilizando técnicas como a mutagênese e a modelagem computacional podem ser úteis nesse sentido, aumentando o conhecimento sobre os detalhes da relação entre a estrutura da proteína e seu mecanismo de ação.

A discussão sobre a aplicabilidade das PACs na área de Tecnologia de Alimento não é inédita, mas relativamente recente. Atualmente, o custo ainda é um dos maiores entraves para utilização dessas proteínas pela indústria de alimentos. O potencial mercado para as PACs, junto com a limitada disponibilidade em poucas espécies selvagens, criou a necessidade de se buscar fontes alternativas. Há uma grande diversidade de espécies de peixes, insetos, micro-organismos e, principalmente, plantas de clima frio que ainda não foi explorada e pode constituir em novas fontes desse material, reduzindo seu custo comercial.

O Brasil, em suas regiões serranas, como a de Santa Catarina e do Rio Grande do Sul, apresenta diversas espécies vegetais que resistem muito bem ao frio intenso e à geada, especialmente plantas nativas, mas que nunca foram avaliadas em relação à presença de PACs. As condições climáticas nessa região também limitam as oportunidades de cultivo de plantas tradicionais; portanto a valorização das espécies nativas pode representar importantes alternativas futuras para a agricultura local.

Uma vez disponíveis em abundância, seguras e com baixo custo, não há dúvidas em afirmar que essas proteínas podem representar uma nova ferramenta na conservação da qualidade de alimentos congelados.

\section{Agradecimentos}

Projeto apoiado com recursos do Edital Universal 14/2014/PROPPI do Instituto Federal de Educação, Ciência e Tecnologia (IFSC) e do Edital Universal MCTI/CNPq 14/2014 do Conselho Nacional de Desenvolvimento Científico e Tecnológico (CNPq).

\section{Referências}

ANTIKAINEN, M.; GRIFFITH, M. Antifreeze protein accumulation in freezing-tolerant cereals. Physiologia Plantarum, Helsinki, v. 99, n. 3, p. 423-432, 1997. http://dx.doi. org/10.1111/j.1399-3054.1997.tb00556.x.

ANTSON, A. A.; SMITH, D. J.; ROPER, D. I.; LEWIS, S.; CAVES, L. S. D.; VERMA, C. S.; BUCKLEY, S. L.; LILLFORD, P. J.;
HUBBARD, R. E. Understanding the mechanism of ice binding by type III antifreeze proteins. Journal of Molecular Biology, Londres, v. 305, n. 4, p. 875-889, 2001. http://dx.doi.org/10.1006/ jmbi.2000.4336. PMid:11162099.

ATICI, O.; NALBANTOGLU, B. Antifreeze proteins in higher plants. Phytochemistry, Amsterdam, v. 64, n. 7, p. 11871196, 2003. http://dx.doi.org/10.1016/S0031-9422(03)00420-5. PMid:14599516.

BAARDSNES, J.; KONDEJEWSKI, L. H.; HODGES, R. S.; CHAO, H.; KAY, C.; DAVIES, P. L. New ice-binding face for type I antifreeze protein. FEBS Letters, Amsterdam, v. 463, n. 1-2, p. 87-91, 1999. http://dx.doi.org/10.1016/S0014-5793(99)01588-4. PMid:10601644.

BILDANOVA, L. L.; SALINA, E. A.; SHUMNY, V. K. Main properties and evolutionary features of antifreeze proteins. Russian Journal of Genetics: Apllied Research, Moscou, v. 3, n. 1, p. 66-82, 2013. http://dx.doi.org/10.1134/S207905971301005X.

BOONSUPTHIP, W.; LEE, T. Application of antifreeze protein for food preservation: effect of type III antifreeze protein for preservation of gel forming of frozen and chilled actomyosin. Journal of Food Science, Chicago, v. 68, n. 5, p. 1804-1809, 2003. http://dx.doi.org/10.1111/j.1365-2621.2003.tb12333.x.

CAI, Y.; LIU, S.; LIAO, X.; DING, Y.; SUN, J.; ZHANG, D. Purification and partial characterization of antifreeze proteins from leaves of Ligustrum lucidum Ait. Food and Bioproducts Processing, Amsterdam, v. 89, n. 2, p. 98-102, 2011. http:// dx.doi.org/10.1016/j.fbp.2010.04.002.

CLEMMINGS, J. F.; ZOERB, H. F.; ROSENWALD, D. R.; HUANG, V. T. Ice cream containing antifreeze protein: new patents. Trends in Food Science \& Technology, Amsterdam, v. 8, n. 12, p. 425, 1997. http://dx.doi.org/10.1016/S0924-2244(97)88211-8.

CREVEL, R. W. R.; FEDYK, J. K.; SPURGEON, M. J. Antifreeze proteins: characteristics, occurrence and human exposure. Food and Chemical Toxicology, Amsterdam, v. 40, n. 7, p. 899-903, 2002. http://dx.doi.org/10.1016/S0278-6915(02)00042-X. PMid:12065210

CRUZ, R. M. S.; VIEIRA, M. C.; SILVA, C. L. M. The response of watercress (Nasturtium officinale) to vacuum impregnation: effect of an antifreeze protein type I. Journal of Food Engineering, Amsterdam, v. 95, n. 2, p. 339-345, 2009. http:// dx.doi.org/10.1016/j.jfoodeng.2009.05.013.

DAVIES, P. L. Ice-binding proteins: a remarkable diversity of structures for stopping and starting ice growth. Trends in Biochemical Sciences, Amsterdam, v. 39, n. 11, p. 548-555, 2014.

DING, X.; ZHANG, H.; CHEN, H.; WANG, L.; QIAN, H.; QI, X. Extraction, purification and identification of antifreeze proteins from cold acclimated malting barley (Hordeum vulgare L.). Food Chemistry, Amsterdam, v. 175, n. 1, p. 74-81, 2015. http:// dx.doi.org/10.1016/j.foodchem.2014.11.027. PMid:25577053. 
Revisão: Proteínas anticongelantes - uma tecnologia emergente para o congelamento de alimentos PROVESI, J. G. e AMANTE, E. R.

DING, X.; ZHANG, H.; LIU, W.; WANG, L.; QIAN, H.; QI, X. Extraction of carrot (Daucus carota) antifreeze proteins and evaluation of their effects on frozen white salted noodles. Food Bioprocess Technology, New York, v. 7, n. 3, p. 842-852, 2014. http://dx.doi.org/10.1007/s11947-013-1101-0.

DUMAN, J. G. Purification and characterization of a thermal hysteresis protein from a plant, the bittersweet nightshade Solanum dulcamara. Biochimica et Biophysica Acta, Amsterdam, v. 1206, n. 1, p. 129-135, 1994. http://dx.doi. org/10.1016/0167-4838(94)90081-7. PMid:8186242.

DUMAN, J. G.; BENNETT, V.; SFORMO, T.; HOCHSTRASSER, R.; BARNES, B. M. Antifreeze proteins in Alaskan insects and spiders. Journal of Insect Physiology, Amsterdam, v. 50, n. 4, p. 259-266, 2004. http://dx.doi.org/10.1016/j.jinsphys.2003.12.003. PMid:15081818.

DUMAN, J. G.; WISNIEWSKI, M. J. The use of antifreeze proteins for frost protection in sensitive crop plants. Environmental and Experimental Botany, Amsterdam, v. 106, n. 1, p. 60-69, 2014. http://dx.doi.org/10.1016/j.envexpbot.2014.01.001.

EWART, K. V.; LIN, Q.; HEW, C. L. Structure, function and evolution of antifreeze proteins. CMLS Cellular and Molecular Life Sciences, Basel, v. 55, n. 2, p. 271-283, 1999. http://dx.doi. org/10.1007/s000180050289. PMid:10188586.

FEENEY, R. E.; YEH, Y. Antifreeze proteins: current status and possible food uses. Trends in Food Science \& Technology, Amsterdam, v. 9, n. 3, p. 102-106, 1998. http://dx.doi. org/10.1016/S0924-2244(98)00025-9.

GAUKEL, V.; LEITER, A.; SPIE , W. E. L. Synergism of different fish antifreeze proteins and hydrocolloids on recrystallization inhibition of ice sucrose solutions. Journal of Food Engineering, Londres, v. 141, n. 1, p. 44-50, 2014. http://dx.doi.org/10.1016/j. jfoodeng.2014.05.016.

GOFF, H. D. Food at subzero temperatures. In: DUTCHER, J. R.; MARANGONI, A. G. Soft materials structure and dynamics. New York: Marcel Dekker, 2005. cap. 12, p. 229-320.

GÓMEZ GALINDO, F.; ELIAS, L.; GEKAS, V.; HERPPICH, W. B.; SMALLWOOD, M.; SOMMARIN, M.; WORRALL, D.; SJÖHOLM, I. On the induction of cold acclimation in carrots (Daucus carota L.) and its influence on storage performance. Food Research International, Amsterdam, v. 38, n. 1, p. 29-36, 2005. http:// dx.doi.org/10.1016/j.foodres.2004.07.004.

GRIFFITH, M.; ALA, P.; YANG, D. S. C.; HON, W. C.; MOFFATT, B. A. Antifreeze protein produced endogenously in winter rye leaves. Plant Physiology, Waterbury, v. 100, n. 2, p. 593-596, 1992. http://dx.doi.org/10.1104/pp.100.2.593. PMid:16653033.

GRIFFITH, M.; ANTIKAINEN, M.; HON, W.; PIHAKASKIMAUNSBACH, K.; YU, X.; CHUN, J. U.; YANG, D. S. C. Antifreeze proteins in winter rye. Physiologia Plantarum, Lund, v. 100, n. 2, p. 327-332, 1997.
GRIFFITH, M.; EWART, K. V. Antifreeze proteins and their potential use in frozen foods. Biotechnology Advances, Londres, V. 13, n. 3, p. 375-402, 1995. http://dx.doi.org/10.1016/07349750(95)02001-J. PMid:14536093.

GRIFFITH, M.; YAISH, M. W. F. Antifreeze proteins in overwintering plants: a tale of two activities. Trends in Plant Science, Amsterdam, v. 9, n. 8, p. 399-405, 2004. http://dx.doi. org/10.1016/j.tplants.2004.06.007. PMid:15358271.

HASSAS ROUDSARI, M. Extraction, purification and study of the mechanism of action of apoplastic ice structuring proteins from cold acclimated winter wheat leaves. 2011. $151 \mathrm{f}$. Tese (Doutorado)-University of Guelph, Guelph, 2011. Disponível em: <https://dspace.lib.uoguelph.ca/xmlui/bitstream/ handle/10214/2987/Final\%20Thesis.pdf>. Acesso em: 24 fev. 2014.

HASSAS ROUDSARI, M.; GOFF, D. Ice structuring proteins from plants: mechanism of action and food application. Food Research International, Amsterdam, v. 46, n. 1, p. 425-436, 2012. http://dx.doi.org/10.1016/j.foodres.2011.12.018.

HON, W. C.; GRIFFITH, M.; CHONG, P.; YANG, D. Extraction and isolation of antifreeze proteins from winter rye (Secale cereale L.) leaves. Plant Physiology, Waterbury, v. 104, n. 3, p. 971-980, 1994. PMid:12232141.

HUANG, T.; DUMAN, J. G. Cloning and characterization of a thermal hysteresis (antifreeze) protein with DNA-binding activity from winter bittersweet night-shade, Solanum dulcamara. Plant Molecular Biology, Dordrecht, v. 48, n. 4, p. 339-350, 2002.

JARZABEK, M.; PUKACKI, P. M.; NUC, K. Cold-regulated proteins with potent antifreeze and cryoprotective activities in spruces (Picea spp.). Cryobiology, Amsterdam, v. 58, n. 3, p. 268-274, 2009.

KONTOGIORGOS, V.; GOFF, H. D.; KASAPIS, S. Effect of aging and ice-structuring proteins on the physical properties of frozen flour-water mixtures. Food Hydrocolloids, Oxford, v. 22, n. 6, p. 1135-1147, 2008. http://dx.doi.org/10.1016/j. foodhyd.2007.06.005.

LAUERSEN, K. J.; BROWN, A.; MIDDLETON, A.; DAVIES, P. L.; WALKER, V. K. Expression and characterization of an antifreeze protein from the perennial rye grass, Lolium perenne. Cryobiology, Amsterdam, v. 62, n. 3, p. 194-201, 2011. http:// dx.doi.org/10.1016/j.cryobiol.2011.03.003. PMid:21457707.

LI, L.; KIM, Y.; HUANG, W.; JIA, C.; XU, B. Effects of ice structuring proteins on freeze-thaw stability of corn and wheat starch gels. Cereal Chemistry, Amsterdam, v. 87, n. 5, p. 497-503, 2010. http://dx.doi.org/10.1094/CCHEM-01-10-0013.

LILLFORD, P. J.; HOLT, C. B. Antifreeze proteins. Journal of Food Engineering, Londres, v. 22, n. 1-4, p. 475-482, 1994. http://dx.doi.org/10.1016/0260-8774(94)90048-5.

LIM, Z. L.; LOW, N. H.; MOFFATT, B. A.; GRAY, G. R. Gelation in protein extracts from cold acclimated and non-acclimated winter 
Revisão: Proteínas anticongelantes - uma tecnologia emergente para o congelamento de alimentos PROVESI, J. G. e AMANTE, E. R.

rye (Secale cereale L. cv Musketeer). Cryobiology, Amsterdam, v. 66, n. 2, p. 156-166, 2013. http://dx.doi.org/10.1016/j. cryobiol.2013.01.001. PMid:23348601.

LIU, K.; JIA, Z.; CHEN, G.; TUNG, C.; LIU, R. Systematic size study of an insect antifreeze protein and its interaction with ice. Biophysical Journal, Cambridge, v. 88, n. 2, p. 953-958, 2005. http://dx.doi.org/10.1529/biophysj.104.051169. PMid:15713600.

MADURA, J. D.; WIERZBICKI, A. Modeling of antifreeze proteins. In: LESZCZYNSKI, J. Computational molecular biology. Amsterdam: Elsevier B. V., 1999. cap. 14, p. 537-568. v. 8. http:// dx.doi.org/10.1016/S1380-7323(99)80089-2.

MARENTES, E.; GRIFFITH, M.; MLYNARZ, A.; BRUSH, R. A. Proteins accumulate in the apoplast of winter rye leaves during cold acclimation. Physiologia Plantarum, Lund, v. 87, n. 4, p. 499-507, 1993. http://dx.doi.org/10.1034/j.13993054.1993.870409.x.

MEYER, K.; KEIL, M.; NALDRETT, M. J. A leucine-rich repeat protein of carrot that exhibits antifreeze activity. FEBS Letters, Amsterdam, v. 447, n. 2-3, p. 171-178, 1999. http://dx.doi. org/10.1016/S0014-5793(99)00280-X. PMid:10214940.

MIDDLETON, A. J.; MARSHALL, C. B.; FAUCHER, F.; BAR-DOLEV, M.; BRASLAVSKY, I.; CAMPBELL, R. L.; WALKER, V. K.; DAVIES, P. L. Antifreeze protein from freeze-tolerant grass has a beta-roll fold with an irregularly structured ice-binding site. Journal of Molecular Biology, Amsterdam, v. 416, n. 5, p. 713-724, 2012. http://dx.doi.org/10.1016/j.jmb.2012.01.032. PMid:22306740.

PAYNE, S. R.; SANDFORD, D.; HARRIS, A.; YOUNG, O. A. The effects of antifreeze proteins on chilled and frozen meat. Meat Science, Londres, v. 37, n. 3, p. 429-438, 1994. http://dx.doi. org/10.1016/0309-1740(94)90058-2. PMid:22059547.

PAYNE, S. R.; YOUNG, O. A. Effects of pre-slaughter administration of antifreeze proteins on frozen meat quality. Meat Science, Londres, v. 41, n. 2, p. 147-155, 1995. http://dx.doi. org/10.1016/0309-1740(94)00073-G. PMid:22060165.

PUDNEY, P. D. A.; BUCKLEY, S. L.; SIDEBOTTOM, C. M.; TWIGG, S. N.; SEVILLA, M. P.; HOLT, C. B.; ROPER, D.; TELFORD, J. H.; MCARTHUR, A. J.; LILLFORD, P. J. The physico-chemical characterization of a boiling stable antifreeze protein from a perennial grass (Lolium perenne). Archives of Biochemistry and Biophysics, San Diego, v. 410, n. 2, p. 238-245, 2003. http:// dx.doi.org/10.1016/S0003-9861(02)00697-5. PMid:12573283.

QIU, L.; MAO, X.; HOU, F.; MA, J. A novel function: thermal protective properties of an antifreeze protein from the summer desert beetle Microdera punctipennis. Cryobiology, Amsterdam, v. 66, n. 1, p. 60-68, 2013. http://dx.doi.org/10.1016/j. cryobiol.2012.11.005. PMid:23187046.

SALVAY, A. G.; GABEL, F.; PUCCI, B.; SANTOS, J.; HOWARD, E. I.; EBEL, C. Structure and interactions of fish type III antifreeze protein in solution. Biophysical Journal, Cambridge, v. 99, n.
2, p. 609-618, 2010. http://dx.doi.org/10.1016/j.bpj.2010.04.030. PMid:20643081.

SIDEBOTTOM, C.; BUCKLEY, S.; PUDNEY, P.; TWIGG, S.; JARMAN, C.; HOLT, C.; TELFORD, J.; MCARTHUR, A.; WORRALL, D.; HUBBARD, R.; LILLFORD, P. Heat-stable antifreeze protein from grass. Nature, New York, v. 406, n. 6793, p. 256, 2000. http://dx.doi.org/10.1038/35018639. PMid:10917518.

SIMPSON, D. J.; SMALLWOOD, M.; TWIGG, S.; DOUCET, C. J.; ROSS, J.; BOWLES, D. J. Purification and characterisation of an antifreeze protein from Forsythia suspensa (L.). Cryobiology, Amsterdam, v. 51, n. 2, p. 230-234, 2005. http://dx.doi. org/10.1016/j.cryobiol.2005.06.005. PMid:16098506.

SMALLWOOD, M.; WORRALL, D.; BYASS, L.; ELIAS, L.; ASHFORD, D.; DOUCET, C. J.; HOLT, C.; TELFORD, J.; LILLFORD, P.; BOWLES, D. J. Isolation and characterization of a novel antifreeze protein from carrot (Daucus carota). The Biochemical Journal, Londres, v. 340, n. Pt 2, p. 385-391, 1999. http://dx.doi.org/10.1042/0264-6021:3400385. PMid:10333479.

TALENS, P.; ESCRICHE, I.; MARTÍNEZ-NAVARRETE, N.; CHIRALT, A. Influence of osmotic dehydration and freezing on the volatile profile of kiwi fruit. Food Research International, Amsterdam, v. 36, n. 6, p. 635-642, 2003. http://dx.doi.org/10.1016/S09639969(03)00016-4

TSVETKOVA, N. M.; PHILLIPS, B. L.; KRISHNAN, V. V.; FEENEY, R. E.; FINK, W. H.; CROWE, J. H.; RISBUD, S. H.; TABLIN, F.; $Y E H, Y$. Dynamics of antifreeze glycoproteins in the presence of ice. Biophysical Journal, Cambridge, v. 82, n. 1, p. 464-473, 2002. http://dx.doi.org/10.1016/S0006-3495(02)75411-8. PMid:11751333.

UNILEVER. (Rotterdam, Holanda). Adrian Daniel, Ian Lacy, Jon Richard Oldroyd. Uso de proteínas anticongelantes en productos de conflitura helada. ES n. 2187 459, 2 mar. 2000, 5 dez. 2001.

URRUTIA, M. E.; DUMAN, J. G.; KNIGHT, C. A. Plant thermal hysteresis proteins. Biochimica et Biophysica Acta, Amsterdam, v. 1121, n. 1-2, p. 199-206, 1992. http://dx.doi. org/10.1016/0167-4838(92)90355-H. PMid:1599942.

VELICKOVA, E.; TYLEWICZ, U.; DALLA ROSA, M.; WINKELHAUSEN, E.; KUZMANOVA, S.; GÓMEZ GALINDO, F. Effect of vacuum infused cryoprotectants on the freezing tolerance of strawberry tissues. LWT - Food Science and Technology, Amsterdam, v. 52, n. 2, p. 146-150, 2013. http:// dx.doi.org/10.1016/j.Iwt.2011.09.013.

VIEIRA, C. R. Proteína estruturadora de gelo em cultivares brasileiras de trigo e centeio: ocorrência, caracterização e aplicação em massas congeladas. 2011. 72 f Tese (Doutorado em Ciência e Tecnologia de Alimentos)-Universidade Federal de Viçosa, Viçosa, 2011

WANG, L. H.; WUSTEMAN, M. C.; SMALLWOOD, M.; PEGG, D. E. The stability during low-temperature storage of an antifreeze protein isolated from the roots of cold-acclimated carrots. 
Revisão: Proteínas anticongelantes - uma tecnologia emergente para o congelamento de alimentos PROVESI, J. G. e AMANTE, E. R.

Cryobiology, Amsterdam, v. 44, n. 3, p. 307-310, 2002. http:// dx.doi.org/10.1016/S0011-2240(02)00036-6. PMid:12237096.

WANG, S.; ZHAO, J.; CHEN, L.; ZHOU, Y.; WU, J. Preparation, isolation and hypothermia protection activity of antifreeze peptides from shark collagen. LWT - Food Science and Technology, Amsterdam, v. 55, n. 1, p. 210-217, 2014.

WANG, W.; WEI, L. Purification of boiling-soluble antifreeze protein from the legume Ammopiptanthus mongolicus. Preparative Biochemistry \& Biotechnology, Oxford, v. 33, n. 1, p. 67-80, 2003. http://dx.doi.org/10.1081/PB-120018370. PMid:12693816.

WEN-LI, X.; MEI-QIN, L.; XIN, S.; CUN-FU, L. Expression of a carrot $36 \mathrm{kD}$ antifreeze protein gene improves cold stress tolerance in transgenic tobacco. Forestry Studies in China, Beijing, v. 7, n. 4, p. 11-15, 2005.

WHARTON, D. A.; POW, B.; KRISTENSEN, M.; RAML ØV, H.; MARSHALL, C. J. Ice-active proteins and cryoprotectants from the New Zealand alpine cockroach, Celatoblatta quinquemaculata. Journal of Insect Physiology, Amsterdam, v. 55, n. 1, p. 27-31, 2009. http://dx.doi.org/10.1016/j.jinsphys.2008.09.007. PMid:18955061.

WHATEN, B.; JIA, Z. Controlling the freezing process with antifreeze proteins. In: SUN, D. Emerging technologies for food processing. London: Elsevier Academic Press, 2005. cap. 25, p. 653-673.

WISNIEWSKI, M.; WEBB, R.; BALSAMO, R.; CLOSE, T. J.; YU, X.; GRIFFITH, M. Purification, immunolocalization, cryoprotective, and antifreeze activity of PCA60: a dehydrin from peach. Physiologia Plantarum, Lund, v. 105, n. 4, p. 600-608, 1999. http://dx.doi.org/10.1034/j.1399-3054.1999.105402.x.

WORRALL, D.; ELIAS, L.; ASHFORD, D.; SMALLWOOD, M.; SIDEBOTTOM, C.; LILLFORD, P.; TELFORD, J.; HOLT, C.; BOWLES, D. A carrot leucine-rich-repeat protein that inhibits ice recrystallization. Science, Washington, v. 282, n. 5386, p.
115-117, 1998. http://dx.doi.org/10.1126/science.282.5386.115. PMid:9756474.

YEH, C. M.; KAO, B. Y.; PENG, H. J. Production of a recombinant type 1 antifreeze protein analogue by L. lactis and its applications on frozen meat and frozen dough. Journal of Agricultural and Food Chemistry, Washington, v. 57, n. 14, p. 6216-6223, 2009. http://dx.doi.org/10.1021/jf900924f. PMid:19545118.

YONG, J.; FEI, Y.; WEI, L. Purification and identification of an antifreeze protein from the leaves of Ammopiptanthus mongolicus. Physiology and Molecular Biology of Plants, Lucknow, v. 6, n. 1, p. 67-73, 2000.

ZHANG, C.; ZHANG, H.; WANG, L.; ZHANG, J.; YAO, H. Purification of antifreeze protein from wheat bran (Triticum aestivum L.) based on its hydrophilicity and ice-binding capacity. Journal of Agricultural and Food Chemistry, Washington, v. 55 , n. 19, p. 7654-7658, 2007a. http://dx.doi.org/10.1021/ jf0715065. PMid:17715897.

ZHANG, C.; ZHANG, H.; WANG, L. Effect of carrot (Daucus carota) antifreeze proteins on the fermentation capacity of frozen dough. Food Research International, Amsterdam, v. 40, n. 6, p. 763-769, 2007b. http://dx.doi.org/10.1016/j. foodres.2007.01.006

ZHANG, C.; ZHANG, H.; WANG, L.; GUO, X. Effect of carrot (Daucus carota) antifreeze proteins on texture properties of frozen dough and volatile compounds of crumb. LWT - Food Science and Technology, v. 41, n. 6, p. 1029-1036, 2008. http:// dx.doi.org/10.1016/j.Iwt.2007.07.010.

ZHANG, D. Q.; LIU, B.; FENG, D. R.; HE, Y. M.; WANG, J. F. Expression, purification, and antifreeze activity of carrot antifreeze protein and its mutants. Protein Expression and Purification, Amsterdam, v. 35, n. 2, p. 257-263, 2004. http:// dx.doi.org/10.1016/j.pep.2004.01.019. PMid:15135400. 